\title{
PARA ONDE VAI O MULTILATERALISMO NAS AMÉRICAS? PROJETOS SUPERPOSTOS NUM PERÍODO DE MUDANÇAS GLOBAIS*
}

Carlos Portales

A proliferação de novos organismos internacionais durante as últimas décadas e o aparecimento de diversas "referências" na América Latina e no Caribe (ALC) é um fenômeno que expressa mudanças mais profundas nas relações internacionais da região, que não se restringem ao hemisfério, como durante a Guerra Fria, mas que se abrem para perspectivas mais globais.

Em primeiro lugar, o alcance do termo "região" está em questão. Em algumas análises se dá a ele o sentido hemisférico, pan-americano - a antiga ideia de Hemisfério Ocidental, materializada na Organização dos Estados Americanos (OEA) em 1948, nas Cúpulas das Américas em 1994 e buscada na Área de Livre Comércio das Américas (Alca). E "região" também pode referir-se ao espaço da ALC, projeto com raízes bolivarianas pós-independentistas e com vínculos mais recentes com o Grupo do Rio, desde 2012 Comunidade dos Estados Latino-Americanos e Caribenhos (Celac).

"Este artigo, “¿A donde va el multilateralismo en las Américas? Proyectos superpuestos en un período de cambios globales", foi traduzido por Fernando Pinheiro. 
Outros, como a União das Nações Sul-Americanas (Unasul), de 2008, usam o termo para conotar espaços mais circunscritos, no caso a América do Sul. Ele deve agregar ainda as sub-regiões: o Caribe (Comunidade do Caribe, Caricom); a América Central, Sistema de Integração Centro-Americano (Sica); a sub-região andina, Comunidade Andina de Nações (CAN); o Mercado Comum do Sul (Mercosul); e entidades que se referem a grupos organizados com base em políticas comuns diante de terceiros, a Aliança do Pacífico (AP); assim como aquelas com orientação político-ideológica comum, a Alternativa Bolivariana para os Povos de Nossa América (Alba). Recorre-se inclusive ao âmbito dos vínculos histórico-culturais, as Cúpulas Ibero-Americanas, de 1991. Torna-se necessário precisar em que sentido se utiliza o termo "região" e qual é seu alcance.

Para entender o multilateralismo regional, devemos examinar que organismos ou entidades o configuram; em torno 204 de que temas se organiza; e como as transformações do sistema internacional pós-11 de setembro de 2001 - associadas às mudanças sociopolíticas domésticas - condicionam sua evolução. Faremos referência à construção institucional do multilateralismo e aos temas de cooperação (voluntária) ou de integração (por cessão ou ao menos limitação de soberania) centrados em diversas áreas. Analisaremos a natureza jurídica dos organismos, o alcance das obrigações que adquirem os participantes, a tomada de decisões, os mecanismos de solução de controvérsias, os recursos financeiros e de pessoal. Finalmente, exploraremos fontes potenciais de mudança: as políticas externas dos principais atores; suas estratégias de desenvolvimento e sua inserção no sistema internacional; e o modelo de interação ou cooperação visado.

\section{Meio século de multilateralismo}

O multilateralismo regional contemporâneo desenvolve-se no marco das Nações Unidas. O Tratado Interamericano de 
Assistência Recíproca (TIAR) formalizou em 1947 um sistema de segurança hemisférico e em 1948 a Carta de Bogotá outorgou uma nova institucionalidade à ideia pan-americana na OEA. A centralidade das preocupações políticas e de segurança ficou demonstrada entre 1948 e 1959: os órgãos políticos foram convocados sete vezes em casos de conflitos interestatais, golpes de Estado ou ameaças entre países membros (Shaw, pp.72-4).

Os direitos humanos e a democracia aparecem em etapas posteriores da OEA. Ainda que a Declaração Americana dos Direitos e Deveres do Homem tenha precedido a Declaração Universal dos Direitos Humanos, o sistema interamericano estabeleceu a Comissão Interamericana de Direitos Humanos (CIDH) apenas em 1959. A criação de uma Corte Interamericana de Direitos Humanos demoraria outra década (Goldman, 2009, pp.856-87). A democracia representativa mencionada na Carta permaneceu no plano retórico até os anos 1990. Mesmo que o âmbito econômico tenha sido o de maior interesse para os latino-americanos na criação de um organismo regional no pós-guerra, a cooperação econômica dos Estados Unidos limitou-se ao fomento do investimento privado e a limitados créditos públicos. A ideia de um banco interamericano só foi aceita pelos Estados Unidos na segunda metade dos anos 1950.

Entre 1960 e 1989, a OEA permaneceu como o principal organismo regional nos âmbitos de segurança e política exterior. Os ministros das Relações Exteriores ou o Conselho Permanente reuniram-se em 18 oportunidades entre 1959 e 1982 para tratar de casos de instabilidade na região. Nessa etapa, sete reuniões tiveram como centro a situação de Cuba, sendo a mais crucial a que excluiu esse país, em 1962, de sua participação na OEA. O mecanismo de segurança operou dentro dos parâmetros da Guerra Fria, ainda que também tenha resolvido conflitos interestatais tradicionais. No entanto, a Guerra das Malvinas, em 1982, criou uma fissura importan- 
te entre seus membros e os mecanismos de segurança não voltaram a ser convocados até 1989, situação em que não se autorizou a invasão do Panamá.

Em direitos humanos, a CIDH adquiriu papel cada vez mais importante, preparando informes sobre os países mais afetados e atuando contra sua violação pelas ditaduras sul-americanas. Adotou-se a Convenção Americana de Direitos Humanos (ocorrida em San José de Costa Rica, em 1969) em vigência em 1978. Em 1982, a Corte emitiu sua primeira opinião consultiva e em 1988 sua primeira decisão em assuntos contenciosos. No final desse período, a instalação do sistema interamericano de direitos humanos havia sido completada (Pasqualucci, 2003). A integração econômica não esteve presente no nível hemisférico nesse período, ainda que os Estados Unidos tenham aberto um espaço para apoiar a integração latino-americana por meio do Banco Interamericano de Desenvolvimento (BID).

206 Até 1960, a OEA era a organização regional per se. A ideia de integração latino-americana havia se desenvolvido desde os anos 1950 para superar a crise do modelo de industrialização por substituição de importações. Inspirados em Raúl Prebisch e na Comissão Econômica para a América Latina e o Caribe (Cepal), das Nações Unidas, buscava-se ampliar os mercados internos sem alterar substancialmente a proteção em relação a terceiros (Mallorquin, 2012, pp.169-96). Foi esse o início das organizações regionais latino-americanas. No entanto, elas não lograram implementar os compromissos assumidos, e muito menos ampliá-los. A Associação Latino-Americana de Livre Comércio (Alalc), de 1960, composta pelo México e países sul-americanos, visava criar uma zona de livre-comércio em doze anos, prazo que foi aumentado para vinte anos em 1969, sem chegar a completar-se (Guerra Borges, 2012). Diante da falta de resultados significativos surgiram projetos sub-regionais. Já em 1969, Bolívia, Chile, Colômbia, Equador e Peru - além da Venezuela (1973) - 
formaram o Pacto Andino, que se traduziria na redução de tarifas alfandegárias inter-regionais e também em políticas comuns de desenvolvimento industrial e de trato do investimento estrangeiro. Em 1976, o Chile retirou-se do Pacto, a iniciativa perdeu seu ímpeto durante a crise dos anos 1980 e também não atingiu seus objetivos.

Na América Central, Guatemala, El Salvador, Honduras, Nicarágua e Costa Rica estabeleceram o Mercado Comum Centro-Americano, em 1960, que chegou a conseguir um comércio recíproco equivalente a um quarto das exportações totais dos países da região no fim dos anos 1970. No entanto, a guerra entre El Salvador e Honduras, em 1969, levou à retirada de Honduras. Tudo isso, somado aos conflitos em El Salvador, àqueles derivados da revolução sandinista na Nicarágua e aos efeitos da crise dos anos 1980, produziu o estancamento do comércio inter-regional e desacreditou as instituições de integração centro-americanas por uma década.

Em síntese, nesse período a OEA foi ampliando sua preocupação temática e excluindo a integração comercial. Essa se colocou como uma aspiração no nível latino-americano e foi implementada em âmbitos sub-regionais, mesmo que sem atingir os objetivos planejados. Os organismos internacionais gerados cumpriam tarefas de acordo com seus tratados constitutivos, mas em áreas que não se sobrepunham.

O fim da Guerra Fria levou à busca de novos paradigmas. No marco de uma revitalização do multilateralismo, as Américas e a ALC seguiram esse caminho. Esse período está marcado por mudanças na região: a abertura à economia internacional, o ocaso das guerras civis centro-americanas e o fim das transições para a democracia nos países do Cone Sul.

A OEA - em que o Canadá havia ingressado em 1990 - adotou o Compromisso de Santiago com a Democracia e a Renovação do Sistema Interamericano em 1991, que 
enunciou novas direções a seguir, e por iniciativa dos Estados Unidos, começou o processo das Cúpulas das Américas, em Miami, em 1994, buscando recolher as convergências que surgiam para a ação multilateral sobre a base da adesão à democracia e a abertura ao livre-comércio, dando novo impulso a um projeto hemisférico. Alcançara-se assim certo consenso, que durou uma década.

Em matéria de segurança hemisférica, a incorporação de novos problemas à agenda (como o narcotráfico, o terrorismo e o crime transnacional organizado) e o impulso dado às medidas de fomento à confiança e à segurança para voltar a abordar os temas interestatais numa OEA renovada expressaram-se na Declaração sobre Segurança nas Américas, no México, em 2003. Essa nova agenda de segurança multidimensional enfatizou a vinculação a diversas agências internacionais em matéria de narcotráfico, terrorismo e segurança cidadã. Por outro lado, as Reuniões Ministeriais de Defesa 208 geraram novo âmbito de contatos entre os países do hemisfério. A OEA manteve certo papel nos temas de prevenção de conflito interestatal.

Em direitos humanos, a CIDH foi seguida pela ação de governos (Argentina, Chile e Uruguai) que estabeleceram procedimentos para enfrentar as violações de direitos humanos em seu passado recente e recebeu convites do Brasil e do México para avaliar sua situação quanto aos direitos humanos. Aumentaram também os casos diante da Corte Interamericana. Por outro lado, durante os anos 1990, vários países aceitaram a jurisdição da Corte, exercida em 2013 sobre 21 Estados.

Uma grande mudança após a Guerra Fria foi a criação de mecanismos multilaterais para a defesa e promoção da democracia na OEA. O Compromisso de Santiago e a Resolução 1.080 (XXI), de 1991, incorporados à Carta pelo Protocolo de Washington, de 1992, permitiram a ação da organização em caso de ruptura de um regime 
democrático. O processo normativo alcançou seu auge com a Carta Democrática Interamericana em 2001. Produziu-se uma transformação na preocupação original pela segurança internacional e proteção à democracia de acordo com os conceitos predominantes no pós-Guerra Fria e concordes com as transformações que se deram na América Latina na década precedente.

A Declaração Iniciativa para as Américas do presidente Bush Jr. preconizou pela primeira vez a integração comercial como programa para o hemisfério. Ideia essa que se tentou implementar durante as administrações Clinton e Bush Jr. por meio das negociações da Alca, mas que não se concretizou.

Paralelamente, os mecanismos de integração na ALC também passaram por profunda modificação após a crise da dívida externa dos anos 1980. O financiamento do Fundo Monetário Internacional (FMI) e do Banco Mundial para enfrentá-la implicou promover reformas de mercado (privatizações, desregulamentações e redução de barreiras comerciais) que foram além do reestabelecimento da estabilidade macroeconômica e abriram as economias latino-americanas às exportações. Nesse marco transformaram-se e foram revitalizados mecanismos de integração comercial, emergindo um "novo regionalismo" ou regionalismo aberto, que não mais visa criar um mercado ampliado com barreiras ao exterior, mas integrar-se para obter vantagens competitivas num processo aberto ao mercado mundial (Giordano e Devlin, 2011).

Uma expressão da mudança nos termos das negociações comerciais foi a criação do Tratado Norte-Americano de Livre Comércio (Nafta, na sigla em inglês) em 1994, o primeiro acordo que incluiu um país latino-americano e os dois países anglo-saxões da América do Norte. Não só acertou-se uma redução de tarifas alfandegárias, mas também regulamentações em diversos âmbitos macroeconômi- 
cos (incluindo comércio de serviços e investimentos), que fixaram um marco para esses países, estabelecendo a maior zona de livre-comércio no hemisfério.

No âmbito latino-americano, os processos regionais de integração comercial revitalizaram-se após a crise dos anos 1980 e muitos dos organismos e entidades passaram a abranger novos âmbitos para além do comercial, incluindo temas de política exterior, segurança, democracia e direitos humanos. Na América Central foi relançado o Sistema de Integração Centro-Americana (Sica), incluindo a participação de Belize e Panamá. O Protocolo de Tegucigalpa, de 1993, ampliou os objetivos, incluindo paz, liberdade, democracia e desenvolvimento. Os avanços logrados no intercâmbio comercial deram-se fortalecendo uma vocação exportadora e de integração com os mercados dos Estados Unidos e Europa. Já os países andinos buscaram em 1989 um redirecionamento do processo de integração sub-regional, aban210 donando o modelo de substituição de importações e fortalecendo os mecanismos de mercado pela via de uma zona de livre-comércio que se aspirava concretizar em 1993. Em 1997 criaram-se estruturas políticas substituindo o Pacto Andino pela Comunidade Andina (CAN) e completou-se a adoção de uma institucionalidade com elementos similares aos europeus. No entanto, os avanços formais não lograram implementação.

A transição para a democracia na Argentina e no Brasil durante os anos 1980 abriu o caminho para uma reavaliação profunda da rivalidade que subjazia a suas políticas externas. O processo de criação de confiança mútua gerado por seus governantes abriu caminho para a cooperação estratégica, cimento da criação - com o Paraguai e o Uruguai - do Mercosul. Seu início foi marcado pelo processo de revitalização da integração com base em economias mais abertas ao mercado internacional. O Mercosul ampliou seu alcance por meio do Foro de Consulta Política, que busca a coordenação 
no âmbito das políticas públicas, especialmente as sociais. Adotou-se também uma cláusula democrática com o Protocolo de Ushuaia em julho de 1998 como resposta ao malogrado golpe contra o presidente Juan Carlos Wasmosy, do Paraguai. No entanto, as crises econômicas no Brasil, de 1998 a 1999, e na Argentina, de 2001 a 2002, acabaram provocando um freio nos avanços da integração e estancaram - quando não reverteram - a abertura para o mundo.

As posições comuns latino-americanas diante das guerras civis na América Central tiveram impacto duradouro na criação de entes políticos que se projetaram em direção ao futuro. A formação do Grupo de Contadora, em 1983 - México, Colômbia, Venezuela e Panamá -, com uma postura de negociação na América Central, e posteriormente com a criação do Grupo de Apoio a Contadora, de 1985 formado pelas novas democracias de Argentina, Brasil, Peru e Uruguai -, e em seguida o processo de Esquipulas, em que a Costa Rica logrou envolver os demais países centro-americanos, geraram outro espaço político. Essas posições comuns constituíram um antecedente fundamental para a formulação de estratégias a partir da ALC. A paz centro-americana contribuiu para impulsionar durante os anos seguintes a integração dessa sub-região. O Grupo do Rio formou-se em 1986 exercendo uma incipiente representação regional informal por um quarto de século.

A defesa da democracia foi preocupação importante do Grupo: o Panamá foi suspenso durante o governo de Manuel Noriega e expulso após a invasão dos Estados Unidos em 1990; o governo de Alberto Fujimori foi suspenso após o autogolpe de 1992; e o Grupo manteve-se atento ao apoiar os processos democráticos na região. Essas preocupações foram complementares às novas instituições de defesa e promoção da democracia pela OEA.

Nesse período também se desenvolveu a Cúpula Ibero-Americana, que reúne os países ibéricos e suas antigas 
colônias na América. Essa comunidade surgiu por iniciativa espanhola, dando conteúdo à nova política internacional da democracia espanhola, fortemente apoiada pela monarquia e inserida no processo de expansão de empresas hispânicas na ALC. A reunião dos chefes de Estado e de governo é acompanhada por reuniões ministeriais de cooperação e intercâmbio entre seus membros.

No fim do milênio, as Américas contavam com numerosos processos multilaterais revitalizados. A integração econômica e comercial tinha pela primeira vez um horizonte comum, havia uma convergência de valores políticos democráticos na quase totalidade dos países e os projetos sub-regionais buscavam uma abertura exterior em diversos graus. A ideia de um espaço hemisférico não era contraposta à de uma voz latino-americana e aceitavam-se as diferenças próprias de cada âmbito. A cobertura temática dos organismos que se desenvolveram chegou a ter muitas áreas de

212 sobreposição. A nova onda multilateral coincidiu com um estreitamento dos entendimentos em temas básicos entre os Estados Unidos e a América Latina, mas sem deixar de lado o crescimento de maior assertividade da ALC em sua atuação política internacional. Essas tendências começaram a contrapor-se na medida em que avançava o novo milênio e mudava a política externa dos Estados Unidos.

\section{Crise do multilateralismo regional e projetos divergentes}

No contexto do pós-11 de setembro de 2001, emergiram importantes diferenças e rupturas na evolução do multilateralismo regional. As mudanças da política externa norte-americana, especialmente a luta antiterrorismo e a guerra do Iraque, assim como as mudanças políticas na ALC, levaram à formação de grupos com posições não apenas diferentes, mas até hostis a Washington. Se em setembro de 2001 a ALC havia dado respaldo aos Estados Unidos pelos atentados terroristas, durante a guerra do Iraque a posição 
da maioria dos países não coincidia mais com a dos Estados Unidos e os dois membros não permanentes do Conselho de Segurança - Chile e México - não apoiaram a autorização para o uso da força solicitado em março de 2003.

A OEA não conseguiu recuperar a primazia nos assuntos de segurança: no âmbito centro-americano continuou exercendo certo papel e tem desempenhado um rol de coadjuvante no processo de desmobilização na Colômbia, mas, em 2012, os quatro países da Alba que ainda pertenciam ao TIAR - Bolívia, Equador, Nicarágua e Venezuela - anunciaram sua retirada desse tratado. Por outro lado, novas iniciativas na América do Sul têm-se ocupado desses assuntos.

A criação de uma área de livre-comércio regional tampouco foi exitosa. As negociações da Alca foram lentas e complexas: em 1995, a I Reunião Ministerial sobre Comércio, ocorrida em Denver, organizou a preparação das negociações, que só tiveram início em 1998. Três rascunhos de texto foram preparados, mas as dificuldades levaram os participantes em 2003, em Miami, a distinguir níveis de compromisso dentro da negociação, aceitando-se uma área comum e acordos adicionais voluntários. Apesar disso, na VI Cúpula em Mar del Plata, em 2005, a Venezuela e os países do Mercosul manifestaram não estarem dadas as condições para finalizá-los, pondo fim a uma década de negociações. O contexto havia mudado, e a visão estratégica de vários dos atores era outra.

Esse processo abriu caminho, no entanto, para numerosos acordos de livre-comércio bilaterais entre Estados Unidos e Chile, em 2004; América Central e República Dominicana (Cafta-RD, em 2006-2009); Peru, em 2009; Panamá, em 2011; e Colômbia, em 2012. E também entre Canadá e Chile, em 1997; Costa Rica, em 2002; Peru, em 2009; e Colômbia, em 2011, agregando-se às negociações já concluídas Panamá, em 2010, e Honduras, em 2011. Antecedendo 
o Nafta, o México havia celebrado um acordo bilateral com o Chile, em 1991, com características similares e estabeleceu também Acordos de Livre Comércio (TLC, na sigla em espanhol) com Colômbia e Venezuela (G-3), em 1995; com a Costa Rica, em 1995; Nicarágua, em 1998; El Salvador, Guatemala e Honduras, em 2001; e Uruguai, em 2004. Essa rede de acordos - associada à que vincula os países latino-americanos entre si - configura o chamado spaghetti bowl, que hoje caracteriza o entrelaçamento de acordos comerciais sobrepostos nas Américas (Giordano e Devlin, 2011).

No plano sub-regional, o processo centro-americano (Sica e acordos com terceiros) fez que as exportações e importações centro-americanas chegassem a representar quase $70 \%$ do PIB da região (comparado a $40 \%$ no resto da ALC) e que na composição de suas exportações passasse a prevalecer as manufaturas - em 1990, dos dez principais produtos exportados para os Estados Unidos oito 214 eram primários, e em 2007 sete eram produtos manufaturados (Beteta, 2012).

Os intentos de fortalecimento da CAN chocaram-se com as mudanças políticas domésticas em vários de seus membros. A Venezuela com Hugo Chávez, a Bolívia sob a presidência de Evo Morales e finalmente o Equador com Rafael Correa criticaram a globalização e a abertura externa de suas economias, retomando orientações protecionistas. As divergências de orientação afetaram principalmente as negociações da CAN com países terceiros e erodiram o projeto comum. Nem a Venezuela, nem a Bolívia nem o Equador aceitaram as negociações com os Estados Unidos. O Peru e a Colômbia obtiveram TLC bilaterais, que entraram em vigor em 2010 e 2012, e a negociação da CAN com a União Europeia (UE) complicou-se e foi rompida em 2008, celebrando-se então um acordo da UE com a Colômbia e o Peru em 2010. A Venezuela havia se retirado da CAN em 2006. A continuidade da CAN só se explica 
por ser ela o marco para as correntes comerciais vigentes entre os atuais membros, que reconhecem preferências especiais para os países de menor desenvolvimento relativo (Bolívia e Equador).

O Mercosul também teve problemas. O objetivo de um mercado comum não foi plenamente alcançado: há setores fora da livre circulação, problemas de coordenação de políticas macroeconômicas têm sido causa de crises, os países menores - Paraguai e Uruguai - sentem-se desfavorecidos e a incorporação das normas do Mercosul aos sistemas nacionais tem sido baixa. Ainda que em 2002 tenha entrado em vigência um Mecanismo de Solução de Controvérsias, na prática os presidentes do Brasil e da Argentina têm resolvido as principais crises do mecanismo (Malamud, 2005, pp.138-64). As políticas econômicas durante o novo milênio não deram continuidade ao aumento da abertura, ressurgindo tendências protecionistas. Contudo, a eliminação de divergências estratégicas entre Brasil e Argentina foi crucial para manter vivo o processo (Gomez Mera, 2005). O Mercosul não obteve acordos comerciais com grandes mercados externos. A recente incorporação da Venezuela após a suspensão do Paraguai, em 2012, e as negociações para o ingresso pleno da Bolívia e eventualmente do Equador assinalam uma mudança de prioridades: a ampliação do bloco sob sua estrita implementação e o aprofundamento das regulações comerciais.

Qual tem sido a evolução dos entes regionais com maior ênfase política? Durante a primeira década do milênio duas tendências se entrecruzaram - maior ampliação e menor profundidade -, mudando a ideia e a prática original. Em primeiro lugar, completou-se a ampliação do Grupo do Rio para todos os países da ALC, com a incorporação de Belize, em 2005; da Guiana, Haiti e Cuba, em 2008; assim como de Suriname e Jamaica, em 2009. Porém, com o ingresso de Cuba - por iniciativa do México -, aban- 
donou-se na prática o requisito do governo democrático como condição de participação. Por outro lado, a partir de 2004, a atividade do Grupo diminuiu: a Cúpula anual realizou-se apenas três vezes. Os países começaram a divergir quanto às formas de exercício da democracia, particularmente em casos de polarização, enfraquecimento da separação de poderes e liberdade de imprensa, mas também no caráter do Grupo do Rio como voz da ALC diante do resto do mundo.

O Brasil reuniu a ALC na cidade de Salvador, em 2008, na Cúpula da América Latina e Caribe sobre Integração e Desenvolvimento (CALC), à margem do Grupo do Rio, provocando a necessidade de redefinir os projetos de cooperação da ALC. A Cúpula Grupo do Rio-CALC, realizada na Riviera Maia, México, em fevereiro de 2010, abriu espaço para a convergência dos processos e a instalação de uma nova referência, denominada Comunidade dos Estados Lati216 no-Americanos e Caribenhos (Celac), com todos os países do hemisfério, exceto Estados Unidos e Canadá. No entanto, a variedade de regimes abrigados na Celac torna menos profundos seus consensos básicos. A democracia permaneceu como declaração geral na agenda comum. A Celac continua como a voz regional nos diálogos com países e grupos de países das Nações Unidas e é a interlocutora com a Europa na Cúpula Celac-UE. Essa vocação foi reivindicada pela troika (Chile, Cuba e Venezuela) em seu giro pela Índia e China, em agosto 2012, para estabelecer diálogos anuais com essas duas potências (Portales, 2012). Contudo, a interlocução regional com a África e com os países árabes reside agora em outra entidade.

A partir de 2004, o panorama chegou a ser ainda mais complexo. Tentam-se formar identidades mais circunscritas: primeiro, a ideia de uma nova (sub)-região sul-americana. Essa visão é principalmente do Brasil, que viu a assinatura do Nafta como o "abandono da região" pelo México e 
considerou as preocupações da América Central e do Caribe como mais vinculadas aos Estados Unidos e alheias aos países sul-americanos. Já em 2000, o Brasil convocou uma Cúpula Sul-Americana, propiciando um diálogo entre as organizações sub-regionais com vista à convergência e pondo ênfase na infraestrutura da integração, na energia, nos transportes e nas telecomunicações. Contudo, esses objetivos foram inicialmente postulados como complementares às iniciativas hemisféricas então em curso, entre elas o Sistema Interamericano de Proteção aos Direitos Humanos (SIPDH), incluindo a integração econômica no hemisfério (Flacso, 2007, pp.15-34). Um passo adicional foi dado em dezembro de 2004 em Cuzco, ao se constituir a Comunidade Sul-Americana de Nações (CSN). Ali se acordou o concerto político e diplomático sul-americano para

[...] afirmar a região como um fator diferenciado e dinâmico em suas relações externas; [...] a convergência entre Mercosul, CAN e Chile com a associação da Guiana e do Suriname; [...] a integração física, energética e de comunicações na América do Sul; [...] a harmonização de políticas [...]; a transferência de tecnologia e de cooperação horizontal [...] [que se obteria] promovendo a convergência, sobre a base da institucionalidade existente, evitando a duplicação e superposição de esforços e sem novos gastos financeiros (Flacso, 2007, pp.83-6).

No entanto, o processo de construção da Comunidade seguiu outros caminhos. Já na Cúpula Energética Sul-Americana na Venezuela, em abril de 2007, a CSN foi rebatizada como União das Nações Sul-Americanas (Unasul) e iniciou-se a negociação de um Tratado Constitutivo de uma nova organização com uma Secretaria Permanente em Quito (Equador), assinada em Brasília, em maio de 2008, entrando em vigor em novembro de 2010 (Sanahuja, 2011). 
Se nos ativermos aos objetivos iniciais da CSN, pode-se concluir que se avançou ao criar uma organização com uma identidade diferenciada. No entanto, a ideia de convergência comercial ficou diluída pela oposição da Venezuela e a coordenação de políticas públicas ficou entregue a reuniões ministeriais paralelas. O objetivo de evitar a duplicação e a superposição de esforços não se cumpriu: a Unasul agregou-se aos processos da CAN e do Mercosul, que mais tarde se sobrepuseram também à Celac.

Quase paralelamente ao projeto sul-americano, o presidente da Venezuela lançou, em 2001, a ideia de uma aliança com um projeto ideológico comum. A Aliança Bolivariana para os Povos de Nossa América Latina (Alba) nasceu como oposição à Alca (Fritz, 2007), buscando uma unidade política. Os países originais foram Venezuela e Cuba. Na III Cúpula da Alba, ocorrida em Havana, em abril de 2006, a Bolívia foi incorporada e assinou-se um Tratado de

218 Comércio dos Povos. Posteriormente incorporaram-se a Nicarágua, em 2007; São Vicente e Granadinas, em 2007; Equador, em 2009; Antígua e Barbuda, em 2009; e Dominica, em 2009. Honduras foi parte da Alba entre 2008 e 2009. A Alba pretende explicitamente construir uma alternativa anti-"integração neoliberal”; está contra as políticas protecionistas e os subsídios dos países industrializados e postula um tratamento especial e diferenciado para seus associados; opõe-se às políticas de ajuste estrutural; favorece a integração latino-americana com uma agenda definida pelos Estados. Elemento-chave para construir essa aliança tem sido a política de créditos para o abastecimento de petróleo ao Caribe (Petrocaribe), vinculada a um fundo Alba-Caribe, de 2005, e a um Tratado Energético Alba, de 2007. Criaram-se ademais projetos na área das comunicações e mecanismos financeiros e seus membros adotaram posições comuns em política externa e nos organizações internacionais (Altmann Borbon, 2011). 
Finalmente, Chile, Colômbia, Peru e México acordaram em junho de 2012 em Paranal, no Chile, a Aliança do Pacífico (AP). Esses países têm seguido políticas econômicas com alto grau de coincidências e têm acordos de livre-comércio entre eles, com os Estados Unidos e com a UE, e alguns também com a China e o Japão. A AP representa $35 \%$ do PIB e mais de $50 \%$ do comércio exterior da ALC. São os países mais abertos ao comércio internacional na região. Três são membros da Cooperação Econômica da Ásia-Pacífico (Apec, na sigla em inglês) - México, em 1993; Chile, em 1994; e Peru, em 1998 - e a Colômbia é candidata. As negociações em curso em 2013 para estabelecer uma área de livre-comércio comum da AP deveriam dar-lhe novo impulso, mas essa organização tem uma vocação de vinculação transregional: seguindo uma proposta de 2002, Chile, Singapura, Nova Zelândia e Brunei assinaram um Acordo de Associação Econômica de caráter transpacífico, em 2006, que serve de base às negociações de um ambicioso Acordo Transpacífico (TPP) de que, com os quatro países originais, participam Estados Unidos, Austrália, Peru, Malásia e Vietnã e a que se incorporaram México, Canadá e Japão.

Se a Caricom e o Sica têm logrado avançar na integração sub-regional, a CAN está virtualmente paralisada e o Mercosul sobreviveu, mas avançando com dificuldades em seu processo interno, com divergências que são produto de mudanças nas políticas econômicas nacionais que têm prevalecido sobre as orientações comunitárias.

Essa proliferação de organismos regionais não só produziu confusão de competências, mas definições distintas e contraditórias de como abordar importantes temas. Desacordos sobre modelos econômicos e sobre sua inserção internacional afetaram os processos de integração comercial; divergências sobre a democracia e os direitos humanos começaram a afetar os mecanismos existentes e levaram à procura, ainda que incipiente, de canais alternativos; 
os temas políticos internacionais e de segurança também foram deslocados para múltiplos cenários; e a proliferação de referências criou mecanismos paralelos de cooperação em políticas públicas. De como se vão articulando e resolvendo essas diferenças depende o destino do regionalismo nas Américas e na ALC. Tem especial importância a atenção às políticas externas desses países e seu efeito nas políticas multilaterais e de integração regional.

\section{Organização e recursos das entidades regionais}

Para entender o alcance e as potencialidades dos organismos e entidades regionais, devemos observar sua organização, o papel de seus órgãos executivos, os recursos humanos e técnicos com que contam sua Secretaria e as tarefas de que estão encarregados.

Em primeiro lugar, distingamos organismos internacionais criados por um tratado e que contam com uma Secre220 taria - OEA, Unasul, Mercosul, Caricom, Sica, Associação Latino-Americana de Integração (Aladi) e a Secretaria Geral Ibero-Americana (Segib) - das entidades que carecem de estrutura administrativa independente formal (Celac e Alba). No caso dos organismos cuja Secretaria é regida por um tratado, podemos encontrar três situações: a OEA, com um secretário-geral com forte procuradoria (com status de chefe de Estado), mais de 650 funcionários e um orçamento de 155,9 milhões de dólares, mais as representações permanentes dos 34 países-membros em Washington (269 diplomatas credenciados) e os 31 escritórios que a OEA tem em Estados-membros.

Contrasta com essa situação a da Unasul e do Mercosul, que têm aparelhos executivos pequenos, com funcionários administrativos sem grandes atribuições e orçamento limitado. Ainda que a Unasul tenha designado secretários-gerais de alto perfil pessoal (ex-presidentes e ex-chanceleres), seu status não ultrapassa o de chefe de Missão, a estru- 
tura administrativa não está completamente estabelecida e o secretário deve atuar com uma Presidência Pro Tempore e com Conselhos de Chanceleres e setoriais.

Numa situação intermediária encontra-se a Caricom, o Sica e em certo sentido a CAN, que têm Secretarias estabelecidas e uma burocracia limitada (Quadro 1). A Aladi é especial, já que conta com um aparato burocrático muito grande em relação às muito escassas funções que conserva. No caso ibero-americano, a Segib cumpre funções principalmente de cooperação e apoio a reuniões ministeriais, mas não de representação política do sistema. Além de sua sede em Madri, tem quatro escritórios na América Latina. A Espanha, país atualmente em crise econômica, é o principal contribuinte.

As outras entidades carecem de estrutura administrativa: a Celac é coordenada por uma Secretaria Pro Tempore (SPT), exercida pelo país organizador da Cúpula, acompanhado por uma troika a que se une um representante da Caricom. Faltam-lhe funcionários e orçamento. As SPT refletem acordos no nível político, mas sem compromissos fortes de implantação de políticas e programas em conjunto. A Celac organizou instâncias interministeriais. A Alba, por sua vez, entregou a implementação de suas tarefas a acordos bilaterais entre seus membros e tem projetos específicos.

Um segundo aspecto a considerar é a distinção entre organismos que se relacionam habitualmente com os membros por meio de embaixadores e missões creditadas na Secretaria (OEA, Aladi) e os casos em que a Secretaria vincula-se a funcionários das capitais, os coordenadores nacionais - geralmente altos funcionários das Chancelarias - no Grupo do Rio, Celac, Cúpula Ibero-Americana, Grupo de Revisão e Implementação de Cúpulas (GRIC) na Cúpula das Américas, ou no Conselho de Delegados da Unasul (Quadro 1). 
No Mercosul, o órgão formal superior é o seu Conselho, composto pelos ministros das Relações Exteriores e da Fazenda ou Economia, e do qual dependem um Grupo Mercado Comum e a Secretaria Administrativa. A criação de um alto representante geral do Mercosul no começo de 2011 visou reforçar "o papel gerador de propostas de políticas regionais e de gestão comunitária”. A renúncia de seu titular, um ano depois de sua nomeação, evidenciou a dificuldade dos governos para assumir uma perspectiva comunitária, particularmente em matérias orçamentárias.

Ainda que o Sica, a Caricom e a CAN tenham estruturas administrativas relativamente complexas, suas Secretarias não têm caráter supranacional, cumprindo funções de apoio a decisões dos respectivos órgãos políticos.

\section{Quadro 1}

Recursos humanos e financeiros dos organismos internacionais da América Latina (2012)

\begin{tabular}{|c|c|c|}
\hline Organismo & Orçamento Anual & Pessoal \\
\hline OEA & US\$ 155.900 .000 & $652+$ \\
\hline Aladi & US\$5.500.000 & 69 \\
\hline Caricom & US\$16.100.000* & n. d. \\
\hline Sica & US\$1.900.000 & 39 \\
\hline Mercosul & US\$2.461.888 & 44 \\
\hline CAN & US\$5.659.000 & 135 \\
\hline Cúpula das Américas & SPT & SPT \\
\hline Celac & SPT & SPT \\
\hline Alba & SPT & SPT \\
\hline Segib & E $\$ 7.000 .000$ & $39 \wedge$ \\
\hline
\end{tabular}

+ 441 profissionais e 231 serviços

* Valor aproximado

n. d.: Não disponível
SPT: Secretaria Pro Tempore. $\wedge$ : mais 17 consultores

Fonte: dados dos organismos. 


\section{A proliferação de entidades e áreas temáticas aumenta a coordenação de políticas?}

A evolução do regionalismo tem gerado sobreposição entre os organismos e as entidades regionais. O Quadro 2 mostra que existem reuniões ministeriais ou de nível semelhante em 33 áreas temáticas que são abordadas paralelamente por oito organismos ou entidades. O que dá origem a 126 processos ministeriais ou de alto nível simultâneos. Essa situação é muito ineficiente como instrumento de coordenação de políticas e torna quase impossível seu acompanhamento pela maioria dos Estados que participam, por carecer de recursos humanos e orçamentários necessários para atender tantos processos. Se considerarmos apenas os quatro mecanismos mais abrangentes territorialmente (OEA/Cúpulas das Américas, Celac, Unasul e Cúpula Ibero-Americana), veremos que sete processos ministeriais são realizados pelas quatro referências, dois processos por três referências entre as quatro e que sete o são por duas entidades. Outro tanto se dá se compararmos a Unasul com o Mercosul, em que se repetem dez processos ministeriais e de funcionários de alto nível.

A prática de processos sobrepostos, superpostos ou paralelos de interação regional conduziu, no melhor dos casos, a intensas trocas de informação sobre políticas mais do que a sua coordenação e harmonização. Tal situação nos leva a refletir sobre para onde se move o centro de gravidade desses processos. Haveria uma vontade de integração ou trata-se apenas de manter mecanismos de associação política para atenuar e manejar as diferenças nos âmbitos regionais e sub-regionais? Nenhum dos mecanismos examinados conta com elementos de supranacionalidade que permita ao menos um trabalho nos Estados para produzir encadeamentos de compromissos e o fortalecimento de uma vontade comunitária. No entanto, há diferenças de grau entre as associações que carecem de qualquer elemento comum e as que são conduzidas por mecanismos pro tempore e aquelas em que 
uma Secretaria Geral poderia oferecer maior continuidade e certa visão coletiva. Contudo, num período de distanciamento de visões entre os atores regionais, mesmo essa capacidade se vê afetada. O encadeamento de interesses comuns pela via do aumento das áreas temáticas perde seu efeito ao diluir-se na repetição.

O seguimento dos acordos dessas reuniões é muito difícil para as estruturas estatais internas dotadas de recursos humanos e orçamentários escassos, para muitas Chancelarias dos países pequenos e mesmo dos médios, mas muito mais para os aparelhos ministeriais setoriais que muitas vezes carecem de equipes internacionais. Tudo isso faz mover o centro de gravidade para os países maiores ou mais ativos em cada organismo ou entidade.

\section{Quadro 2}

\section{Reuniões ministeriais regionais e outras de alto nível}

\begin{tabular}{|c|c|c|c|c|c|c|c|c|}
\hline Organismo & $\begin{array}{l}\text { OEA/ } \\
\text { cúpula }\end{array}$ & Celac & Caricom & Sica & Unasul & Mercosul & CAN & Ibero \\
\hline \multicolumn{9}{|l|}{$\begin{array}{l}\text { Reunião } \\
\text { ministerial }\end{array}$} \\
\hline Relações Ext. & $x$ & $x$ & $x$ & $x$ & $x$ & $x$ & $x$ & $x$ \\
\hline $\begin{array}{c}\text { Interior/Seg. } \\
\text { Pub. }\end{array}$ & $x$ & + & & & $x$ & $x$ & & $x$ \\
\hline Defesa & $x$ & & & $x$ & $x$ & & & \\
\hline Justiça & $x$ & & & & & $x$ & & $x$ \\
\hline Fazenda & & $x$ & $x$ & & $x$ & $x$ & $x$ & $x$ \\
\hline As. Monetária & & & $\#$ & + & & + & & \\
\hline Com. Exterior & * & $\wedge$ & $x$ & $x$ & & $x$ & $x$ & \\
\hline Trabalho & $x$ & & $\#$ & & & $x$ & & $x$ \\
\hline $\begin{array}{l}\text { Seguridade } \\
\text { social }\end{array}$ & & & & & & & & $x$ \\
\hline Ind./Fomento & & + & $\#$ & & & $x$ & & $x$ \\
\hline $\begin{array}{l}\text { Obras Públ./ } \\
\text { Transporte }\end{array}$ & & $x$ & & & $x$ & & $x$ & $x$ \\
\hline
\end{tabular}

continua... 


\begin{tabular}{|c|c|c|c|c|c|c|c|c|}
\hline Organismo & $\begin{array}{l}\text { OEA/ } \\
\text { cúpula }\end{array}$ & Celac & Caricom & Sica & Unasul & Mercosul & CAN & Ibero \\
\hline Moradia & & & & & & & & $x$ \\
\hline Energía & & $x$ & $\#$ & & $x$ & $x$ & & $x$ \\
\hline C\&T & $x$ & $x$ & $\#$ & & $x$ & $x$ & & $x$ \\
\hline $\begin{array}{c}\text { Inovação/ } \\
\text { Conhecimento }\end{array}$ & & & & & & & & $x$ \\
\hline $\begin{array}{l}\text { Sociedade da } \\
\text { Informação }\end{array}$ & & & & & & & & $x$ \\
\hline $\begin{array}{c}\text { Desenvolv. Sust./ } \\
\text { Meio Amb. }\end{array}$ & $x$ & $x$ & $\#$ & $\mathrm{X}$ & & $x$ & + & $x$ \\
\hline Desenvol. Social & $x$ & $x$ & $x$ & $x$ & $x$ & $x$ & & \\
\hline Assistência hum. & & $x$ & & & & & & \\
\hline Mulher/Gênero & $x$ & & $\#$ & $x$ & & + & $x$ & $x$ \\
\hline Juventude & & & $\#$ & & & & & $x$ \\
\hline Infância/Adolesc. & & & & & & & & $x$ \\
\hline Educação & $x$ & & $x$ & $x$ & $x$ & $x$ & $x$ & $x$ \\
\hline Cultura & $x$ & $x$ & $\#$ & $x$ & $x$ & $x$ & $x$ & $x$ \\
\hline Saúde & $x$ & & $\#$ & $x$ & $x$ & $x$ & $x$ & \\
\hline Turismo & $x$ & & & $x$ & & $x$ & + & $x$ \\
\hline Agricultura & $x$ & & \# & $x$ & & $\mathrm{x}$ & + & $x$ \\
\hline Informações & & & & & & & & $x$ \\
\hline Comunicações & & & & & & & & $x$ \\
\hline $\begin{array}{c}\text { Adm. Públ./ } \\
\text { Reforma Estado }\end{array}$ & & & & & & & & $x$ \\
\hline Presidência & & & & & & & & $x$ \\
\hline $\begin{array}{c}\text { Demo/Eleitoral } \\
\text { Democracia }\end{array}$ & + & & & & + & + & & \\
\hline Dir. Hum. & + & & & & & + & & \\
\hline
\end{tabular}

$X$ indica reunião ministerial.

\# indica tarefas encomendadas

expressamente a um dos conselhos

ministeriais da Caricom.

* registra negociações da Alca pelos ministros do Comércio Exterior dos países das Américas, hoje abandonadas. $\wedge$ refere-se a seminário de alto nível sobre a convergência dos processos de integração. + registra a ação de organismos de alto nível intergovernamentais, independentes (no marco da OEA); ou de alto nível não ministeriais (democracia e direitos humanos na Unasul e no Mercosul).

Fonte: sites dos organismos e programas. 


\section{0 papel dos chefes de Estado e de governo no regionalismo latino-americano}

O regionalismo latino-americano tornou-se presidencializado: os chefes de Estado, a partir dos anos 1990, têm desempenhado papel central tanto em termos de impulso como de continuidade do processo, em contraste com as formas de multilateralismo clássico.

No período 1947-1959 houve apenas uma reunião dos presidentes das Américas e não houve cúpulas formais latino-americanas. Entre 1960 e 1989 houve também uma reunião de cúpula presidencial interamericana e três latino-americanas, enquanto em nível sub-regional começava a desenvolver-se o sistema do Caribe com 20 reuniões de chefes de governo e na América Central com 6 cúpulas. Em troca, no período 1990-2003, houve 4 Cúpulas das Américas, 14 latino-americanas, 28 sul-americanas (incluindo o Mercosul), 15 presidenciais andinas, 28 da Caricom e 55

226 reuniões centro-americanas, além de 13 Cúpulas Ibero-Americanas. Finalmente, entre 2004 e 2012 celebraram-se 4 Cúpulas das Américas, 6 latino-americanas, 29 sul-americanas, 9 andinas, 18 caribenhas, 52 centro-americanas, 18 da Alba e 8 Ibero-Americanas.

Fica evidente a mudança de eixo do multilateralismo regional da etapa predominantemente interamericana para uma centrada na ALC e as sub-regiões. Ao somarmos às reuniões presidenciais as de nível de Chancelaria na OEA, e compará-las com as cúpulas da ALC ou sub-regionais somente, temos que entre 1947-1959 houve 5 reuniões interamericanas e nenhuma dos outros mecanismos, e entre 1960-1989 houve 31 interamericanas ante 29 da ALC. A mudança é completa nos períodos seguintes: 24 interamericanas entre 1990-2003 e 153 da ALC; e entre 2004-2012, ante 25 interamericanas, há 140 da ALC.

Esse aumento exponencial dos encontros presidenciais formais facilitou as vinculações pessoais entre os mandatá- 


\section{Quadro 3}

Reuniões de cúpula de autoridades da América Latina (frequência)

\begin{tabular}{|c|c|c|c|c|c|}
\hline Cúpulas & $\begin{array}{c}1947- \\
1959\end{array}$ & $\begin{array}{c}1960- \\
1989\end{array}$ & $\begin{array}{c}1990- \\
\mathbf{2 0 0 3}\end{array}$ & $\begin{array}{c}\mathbf{2 0 0 4} \\
\mathbf{2 0 1 2}\end{array}$ & Total \\
\hline Interamericanas & 1 & 1 & 4 & 4 & 10 \\
\hline OEA (chancelarias) & $(4)$ & $(30)$ & $(20)$ & $(21)$ & $(75)$ \\
\hline Latino-Americanas & - & 3 & 14 & 6 & 23 \\
\hline Do Caribe & - & 20 & 28 & 18 & 66 \\
\hline Centro-Americanas & - & 6 & 55 & 52 & 113 \\
\hline $\begin{array}{c}\text { Sul-Americanas } \\
\text { (inclui Mercosul) }\end{array}$ & - & - & 28 & 29 & 57 \\
\hline Andinas & - & - & 15 & 9 & 24 \\
\hline Alba & - & - & - & 18 & 18 \\
\hline
\end{tabular}

Fonte: sites dos respectivos organismos e entidades deste quadro.

rios, que hoje muitas vezes usam essas ocasiões e a comunicação telefônica direta para tratar de temas bilaterais e multilaterais. De algum modo, a frequência da interação presidencial contribuiu para gerar espaços de consulta no mais alto nível e de fortalecimento de identidades sub-regionais e latino-americanas de maneira muito mais forte que a que se tinha até o fim da Guerra Fria. Esses canais de comunicação fluidos têm aumentado a importância da diplomacia presidencial, produzindo maior flexibilidade, mas também criando novas complexidades na implementação e sequência de muitas iniciativas.

\section{Para onde vai o multilateralismo regional? As chaves que devemos observar}

Como entender esse complexo panorama de proliferação de entidades? Em primeiro lugar, prestaremos atenção às políticas externas dos países envolvidos. Em um período de reestruturação do poder internacional, surgem diver- 
sos intentos nacionais para estabelecer novos arranjos: há "potências emergentes", Estados que pretendem ocupar novos espaços e também a ideia de estabelecer uma voz regional. Nesse contexto deve-se analisar o propósito da associação. Trata-se então de ver se há uma disposição de transferir competências para entes supranacionais ou se o que se quer é preservar uma voz nacional decisiva para as decisões em matéria de cooperação.

Em segundo lugar, é preciso estudar como as políticas de desenvolvimento continuarão determinando o multilateralismo regional: alguns países continuam avançando na abertura de mercados e na procura de novas disciplinas para organizar o intercâmbio e a competência num mundo globalizado (AP), enquanto outros têm preferido variar as negociações com os principais mercados mundiais, esperando reformas mais abrangentes das economias mais desenvolvidas e evitando compromissos que possam limitar o próprio desenvolvimen228 to (Mercosul); e há ainda uma terceira vertente de Estados críticos da globalização com modelos de forte presença estatal e alheios à ideia de livre-comércio (Alba).

Em terceiro lugar, devemos retornar ao conceito de região, desta vez não apenas em sua extensão ou âmbito, mas em sua intenção de integrar unidades nacionais que até agora têm atuado independentemente. O conceito de região pode aparecer só como um âmbito de ação preferencial ou como um espaço que contém atores relacionados num sistema distinguível de outros sistemas. Para que uma região chegue a ter significação política, ela precisa desenvolver uma capacidade de ação comum que se incrementará uma vez que haja propósitos coincidentes, mecanismos efetivos para formular e implementar políticas comuns e finalmente vínculos que permitam sua transformação em uma unidade maior, num processo de integração. Para isso é necessária a provisão de bens públicos comuns que sejam capazes de manter os laços comunitários. 


\section{As complexidades crescentes de segurança na região}

Há uma superposição de organismos e uma ampliação da definição de segurança. Na perspectiva hemisférica, o TIAR continua vigente ainda que com uma cobertura cada vez mais parcial, pela ausência da incorporação de boa parte do Caribe anglófono e do Canadá, pela desistência do México e pela retirada dos países da Alba, formalizada pela Nicarágua, Bolívia e Venezuela. Esses países também anunciaram em 2013 sua retirada dos trabalhos da Junta Interamericana de Defesa. Não obstante, a Conferência de Ministros de Defesa das Américas continua operando. A OEA ainda cumpre funções na resolução de conflitos em algumas sub-regiões. Além disso, tem desenvolvido certa aptidão para enfrentar novas dimensões da segurança multidimensional (terrorismo, segurança cidadã, narcotráfico e crime transnacional organizado) (Herz, 2008). No complexo assunto das drogas e diante da posição revisionista dos presidentes da Colômbia, Guatemala e México e da reticência dos Estados Unidos, a Cúpula de Cartagena deu mandato à OEA para preparar opções para a reflexão dos governos americanos. A Secretaria Geral apresentou um informe para iniciar uma discussão sobre o hemisfério, que começou em maio de 2013.

No âmbito sul-americano constituiu-se paralelamente uma nova referência de segurança: o Conselho de Defesa Sul-Americano da Unasul, em 2009, que está desenvolvendo atividades em política de defesa: cooperação militar, ações humanitárias e operações de paz; cooperação em matéria de indústria e tecnologia de defesa; assim como em formação e capacitação, agenda parcialmente sobreposta à da Conferência de Ministros de Defesa das Américas. A Unasul já havia contribuído politicamente para desativar a situação de violência interna na Bolívia em 2008 e para canalizar a inquietude da maioria dos países da América do Sul pelos acordos entre Colômbia e Esta- 
dos Unidos que permitiam ampliar a presença militar dos Estados Unidos na Colômbia, que finalmente não foram ratificados por esse país.

Um terceiro âmbito é configurado pelo Tratado Marco de Segurança Democrática na América Central, de 1995, que tem buscado fortalecer as instituições e o Estado de Direito, subordinando os militares aos governos democráticos e ao respeito aos direitos humanos. Apesar dos visíveis avanços logrados internamente nessa sub-região, voltaram a surgir conflitos interestatais, que se processaram em âmbito mais amplo e não dentro do Tratado Marco. O tema da droga também tem sido abordado num marco sub-regional centro-americano com outros atores interessados (Estados Unidos, México e Colômbia).

Em síntese, não há uma visão única a respeito do alcance do âmbito da segurança. A antiga estrutura hemisférica tem sofrido golpes graças à decrescente universali230 dade de seu principal instrumento e pelo enfraquecimento do papel da OEA como órgão processador dos conflitos, mesmo que perdure até certo ponto seu papel na diplomacia preventiva. A desistência ativa de um grupo de países (Alba) da ideia mesma de identidade hemisférica tem contribuído para tornar mais complexa a consideração dos temas de segurança nessa perspectiva. Por outro lado, o interesse do Brasil em potencializar o espaço sul-americano como uma região com preocupações independentes tem permitido desenvolver um espaço de relações e laços de segurança não satisfeitos no nível hemisférico (Sanahuja, 2010, pp.111-17). Pode-se formular como hipótese que no contexto de visões diferentes e de políticas externas que buscam ordenar os espaços de perspectivas regionais de alcance distinto, poderiam coexistir acordos complementares - caso se obtivesse um modus vivendi para delimitar seus âmbitos e competências - ou contraditórios, caso não se obtenha tal entendimento. 


\section{Como se estabelece a relação com o mundo globalizado?}

$\mathrm{O}$ regionalismo interamericano pôs acento na segurança coletiva. Quando a ALC começou a adotar posições independentes na OEA, os Estados Unidos privilegiaram o bilateralismo nos conflitos centro-americanos dos anos 1980. Como resultado, a ALC desenvolveu a ideia de uma voz regional por meio do Grupo do Rio. Neste milênio o Brasil, por sua vez, começou a construir a ideia alternativa da América do Sul como novo âmbito de referência regional e a projetar vínculos externos por esse prisma. Adicionalmente, os países da Alba uniram-se na negação do Hemisférico, sem deixar de apoiar organizações alternativas tanto no âmbito latino-americano como sul-americano.

Desde 2004 essa proliferação de referências se manifesta no Grupo do Rio, CALC, Celac, Mercosul, Unasul e Alba. A explicação dessa multiplicidade pode ser encontrada nas políticas externas que as impulsionam: inclusivas da América Latina e do Caribe (México e Chile), de criação de uma nova região - América do Sul - (principalmente Brasil) e de rechaço do interamericano (Alba). As primeiras buscam as vozes comuns, apesar das diferenças em seus projetos de desenvolvimento; as segundas esperam o surgimento de um novo poder emergente, que aspira a um espaço próprio para relacionar-se globalmente; e as terceiras baseiam-se na negação da influência dos Estados Unidos e da globalização.

Assim, no âmbito das relações políticas, o Grupo do Rio estabeleceu diálogos com diversos agrupamentos de países e potências, que foram continuados por meio da Celac nas Nações Unidas e no vínculo entre América Latina e o Caribe-União Europeia (ALC-UE). Nessa direção, a Celac retomou vínculos com a Ásia. Em troca, a Unasul desenvolveu vínculos entre América do Sul e África (ASA) e Cúpula América do Sul-Países Árabes (Aspa).

Por outro lado, se observarmos como se estruturam as relações econômicas internacionais na região, constata-se que 
há um grupo de países que têm Tratados de Livre Comércio (TLC) com os Estados Unidos, Canadá e acordos de associação com a UE (México, Chile, Peru, Colômbia e os centro-americanos) e alguns com os principais países asiáticos (Chile e Peru), enquanto os países do Mercosul e da Alba (com exceção da Nicarágua) carecem desses vínculos.

Determinada definição de região (latino-americana ou sul-americana) não só tem implicação para as relações com terceiros, mas também para os equilíbrios internos de qualquer projeto regional. Em todo caso, nenhum dos atuais projetos de integração regional recebe contribuições substantivas de um ou mais Estados para prover os bens públicos comuns necessários para cimentar uma sólida união regional.

Um elemento adicional para se levar em conta é a participação dos países da região em acertos transregionais. Em primeiro lugar, o envolvimento dos organismos transpacíficos com ênfase no econômico-comercial, refletido na partici232 pação do México, em 1993, do Chile, em 1994, e do Peru, em 1998, no mecanismo de Cooperação Econômica da Ásia-Pacífico (Apec) e na negociação do TPP. Trata-se de uma linha de vinculações ligadas ao modelo econômico de abertura. Em segundo lugar, a participação do Brasil nos acordos entre as potências emergentes, com Rússia, China, Índia e África do Sul (BRICS), e com as duas últimas (IBSA). Trata-se de uma linha de vínculos políticos entre potências emergentes dentro da mudança de poder mundial. E, finalmente, a participação de Brasil, Argentina e México no Grupo dos 20, em que não estabeleceram necessariamente uma visão comum, nem assumiram uma representação regional.

A construção de regiões hoje se dá não apenas sobre a base de âmbitos geográficos contíguos, mas também por afinidades ou interesses transregionais. A tendência a uma multiplicação de referências permanece à medida que a definição dos interesses nacionais e os projetos de desenvolvimento diferentes se mantenham. 


\section{Promoção e proteção dos direitos humanos}

O Sistema Interamericano de Proteção aos Direitos Humanos (SIPDH) é o resultado mais avançado do multilateralismo nas Américas: conta com órgãos independentes, eleitos pelos Estados e autônomos em seu funcionamento para proteger os direitos estabelecidos na Declaração e na Convenção Americana. Os Estados-membros da Convenção Americana sobre Direitos Humanos obrigaram-se a cumprir as resoluções da Corte. Além de observar a situação dos direitos humanos nos países da OEA, a CIDH desenvolveu um sistema que processa mais de 1.500 petições anualmente e adota medidas preventivas em dezenas deles, quando pessoas ou grupos estão em risco de sofrer um dano irreparável a seus direitos. Eventualmente, a CIDH leva os casos à Corte, quando a situação não tenha sido sanada. A CIDH também tem impulsionado um sistema de relatorias para chamar a atenção sobre abusos potenciais na região. Por sua vez, a Corte tem assegurado a justiça em casos de vítimas individuais e sua jurisprudência promoveu doutrinas que levaram a mudanças estruturais destinadas a prevenir futuras violações dos direitos humanos.

O sistema sofreu resistência por parte de alguns Estados em vários momentos: Trinidad e Tobago, em 1998, recusou a Convenção Americana pela aplicação da pena de morte; o Peru, em 1999, durante o governo de Fujimori recusou a Convenção, mas o governo de transição retirou a recusa em 2001 e a Venezuela recusou a Convenção Americana em 2012.

Recentemente, em 2012, em Cochabamba, a Assembleia Geral da OEA abriu um processo de revisão do sistema que levou a CIDH a adotar em 2013 um conjunto de reformas procedimentais com a promessa dos Estados de fortalecer o financiamento do sistema. Ainda que o processo não tenha sido formalmente encerrado, foram obtidos acordos que podem, ao menos de modo temporário, manter esse importante mecanismo de proteção. 
Para além da discussão na OEA, estabeleceram-se mecanismos de direitos humanos nos novos âmbitos regionais. Em 2005 foi organizada a Reunião de Altas Autoridades de Direitos Humanos e Chancelarias do Mercosul e Estados Associados, foro interestatal de análise e definição de políticas públicas com um papel importante na promoção dos direitos humanos e em 2009/2010 criou-se o Instituto de Direitos Humanos do Mercosul. Essas iniciativas fortaleceram o viés dos direitos humanos nas políticas públicas dos países participantes.

A evolução do sistema de proteção dos direitos humanos será um indicador-chave da possibilidade de manter organismos regionais de distinto alcance, mas compatíveis entre si, ou parte-se para a construção de sistemas alternativos que modificariam substancialmente o tratamento multilateral dos direitos humanos na região. De novo nesta dimensão, as políticas externas terão papel-chave: se a apos-

234 ta é na constituição de um sistema alternativo, se insistirá em construí-lo em cada uma de suas dimensões, acentuando as diferenças.

\section{Proteção da democracia na região}

O fortalecimento dos processos democráticos é um objetivo da integração na América Central (Tratado Marco de Segurança Democrática, 1995) e no Mercosul (Protocolo de Ushuaia, 1998). Estabeleceu-se um mecanismo diante de uma "ruptura da ordem democrática", que contempla consultas com o país que apresenta problemas e autoriza seus membros a adotar desde a suspensão da participação no organismo até a suspensão dos direitos e obrigações do país-membro infrator. A Carta Democrática Interamericana, de 2001, não pôde ser aprofundada em razão das diferenças que surgiram quanto ao conceito de democracia e à aplicação do mecanismo, especialmente no tocante ao golpe de Estado na Venezuela em 2002. 
Posteriormente, e como resposta a uma nova crise, a de uma sublevação policial no Equador, a Unasul acordou um Protocolo sobre Compromisso com a Democracia, em 2010,

[...] para ser aplicado em caso de ruptura ou ameaça de ruptura da ordem democrática, de uma violação da ordem constitucional ou qualquer situação que ponha em risco o legítimo exercício do poder e a vigência dos valores e princípios democráticos.

Na prática, no entanto, a crise do Paraguai em 2012, que culminou com a saída do presidente [Fernando] Lugo, produziu respostas diferentes dos sistemas vigentes: a suspensão do Paraguai do Mercosul e Unasul, pelo entendimento de seus membros de que houve golpe de Estado, enquanto a OEA manteve implicitamente o critério da aplicação das regras do juízo político, mantendo a participação do governo do Paraguai.

O objetivo de fortalecer a democracia contou também com o apoio das missões de observação eleitoral. Desde 1989 a OEA deixa à disposição dos Estados-membros mais de 160 missões de observação eleitoral a 24 países da região, que contribuíram para o aperfeiçoamento e credibilidade desses processos. Em 2013 a Unasul enviou uma missão de observação eleitoral à Venezuela, processo para o qual a OEA não foi convidada. Assim, no campo da observação eleitoral coloca-se também o tema da compatibilidade ou complementaridade entre esses mecanismos.

\section{Futuro dos processos de integração econômica}

Em 2012, a Caricom voltou a dar ênfase à revitalização da integração para enfrentar a crise mundial, mesmo havendo um debate sobre a distribuição de custos e benefícios, especialmente no caso da Jamaica (Cepal, 2012, p.126). O Sica fez avanços importantes em sua integração, culminando com 
um TLC único com o México, em 2011, que ampliaria o espaço econômico e se vincularia produtiva e comercialmente aos Estados Unidos. A Caricom e o Sica deveriam continuar e eventualmente aprofundar a integração sub-regional.

Por outro lado, é preciso prestar atenção na ampliação do Mercosul e na consolidação da AP. Trata-se de acordos cuja inserção na economia mundial é distinta. Enquanto o Mercosul não obteve acordos de livre-comércio com os grandes mercados, a AP os possui e busca sua ampliação nas negociações transpacíficas.

A expansão do Mercosul implica acolher uma economia mais bem fechada como a venezuelana no contexto das restrições ao comércio exterior adotadas pela Argentina e pelo Brasil como resposta à situação econômica mundial. A consolidação da AP aposta no acordo de um TLC comum que permita aproveitar as vantagens de sua associação nos mercados externos. Nessa direção aponta também a inicia236 tiva de integração das bolsas de comércio do Chile, Colômbia, Peru e México (Mercados Integrados Latino-Americanos), que começou em 2012. No caso da Alba, o dinamismo dos processos de cooperação interestatal fica muito ligado à capacidade e vontade de uma Venezuela em crise e em processo de incorporação ao Mercosul.

A dinâmica dos processos econômicos não conduz a uma única fórmula de integração, ainda que haja certa preocupação de tentar a interação entre os principais processos existentes, evidenciada no esforço da Celac de promover a coordenação dos mecanismos institucionais de integração e cooperação (Pena, 2010b).

\section{Coordenação de políticas públicas}

A interação constante entre os responsáveis pelas políticas públicas deve levar a melhor conhecimento mútuo. No entanto, a sobreposição de mecanismos pode gerar outros problemas, sem garantir a coordenação. Essa é a chave para 
avançar na cooperação, especialmente se não se acentua a integração por meio do mercado ampliado.

O tema da energia em 2007 foi a bandeira da Unasul como novo processo por meio do projeto do Gasoduto do Sul, mas esse não obteve consenso que superasse as divisões entre modelos de mercado, intervencionista e estatizante (Tissot, 2012).

A repetição de reuniões e de organismos leva à competição por recursos para obter propósitos similares entre referências que agrupam - parcialmente - os mesmos países. Para resolver esse mosaico de processos ministeriais e de organismos de apoio, é central a ideia de racionalização. Porém essa solução pode ser neutralizada por lideranças políticas que buscam dar coerência a diferentes projetos de coordenação alternativos.

\section{A "região" e seus projetos num mundo em transformação}

O multilateralismo regional mostra um hemisfério que se estruturou em torno de uma organização política que, no fim dos anos 1940, encarregou-se dos problemas de segurança regional, a OEA, e que foi capaz nos de 1980 e 1990 de agregar as dimensões de proteção dos direitos humanos e de promoção da democracia como propósitos compartilhados. Por sua vez, a ideia de integração surgiu nos anos 1960 a partir do espaço latino-americano com Alalc, com a Associação de Livre Comércio do Caribe (Carifta, na sigla em inglês), com o Mercado Comum Centro-Americano (MCCA), e depois com o Pacto Andino. Os anos 1990 caracterizaram-se também pela virada de uma integração fechada ao mercado mundial para um regionalismo aberto, com a CAN, o Sica, em certo sentido o Mercosul e principalmente os TLC, a par com o nascimento de uma organização política da voz latino-americana, o Grupo do Rio.

O novo milênio abre-se com o fracasso do projeto hemisférico de livre-comércio (Alca), e os caminhos da 
integração voltam a separar-se entre os que perseveram no comércio aberto (México, Chile, Peru, Colômbia e os países centro-americanos) e os que buscam formas reguladas - alguns conservando as formas de mercado ampliado parcialmente aberto (Mercosul) e outros substituindo-as por acordos interestatais (Alba). Paralelamente, desenvolvem-se as formas de cooperação política sobre a base de diferentes eixos (Celac e Unasul).

Como resultado, predominam hoje formas de integração econômica débeis e geograficamente mais difusas e um regionalismo que põe acento na identidade política, nos temas de segurança e na integração física, com baixo componente de institucionalização (Malamud e Gardini, 2012).

A participação nos projetos de integração ou cooperação não é excludente, de modo que os países têm múltiplos pertencimentos, criando-se tensões e diminuindo sua eficácia. A retórica substitui o conteúdo, havendo uma brecha 238 entre as declarações acordadas e as ações implementadas.

Por traz de cada projeto percebe-se a política externa dos países que têm ou buscam projeção no mundo: originalmente os Estados Unidos na OEA e, no novo milênio, o Brasil no Mercosul e na Unasul e a Venezuela na Alba (Serbin, 2010). No entanto, o Estados Unidos, depois do fracasso da Alca, não propôs uma nova política regional consistente; o Brasil está levando a cabo dois projetos ao mesmo tempo (Unasul e Mercosul), sem tentar fundi-los; já a Venezuela, que usou seus recursos de petróleo na articulação da Alba, conseguiu mais uma política exterior comum, alternativa ao projeto hemisférico, do que um processo de integração profundo, e agora se incorpora ao Mercosul. Os demais países esperam que as formas de associação novas e antigas passem a refletir mais equilibradamente seus interesses, incluindo diferentes modalidades de vinculação global. Os países da AP, além de avançar em sua integração, aspiram aprofundar sua inserção nas negociações transpacíficas. 
Os vínculos políticos com outras regiões têm seguido diferentes caminhos: o da ALC com a União Europeia e com alguns países da Ásia, o sul-americano com a África e países árabes. Porém, em nível mundial, não se constituiu uma representação regional propriamente dita: os países que participam do Grupo dos 20 (Argentina, Brasil e México) o fazem individualmente, sem coordenação entre si, nem com o resto da região. O Brasil atua assim no BRICS e na IBSA. Mesmo que haja uma "voz regional" tênue presente em certos diálogos inter-regionais, essa não tem presença nas novas instâncias que buscam a reestruturação do poder mundial, nem no plano dos acordos comerciais compreensivos que gerem mercados ampliados e habilitem uma integração produtiva mais permanente.

No curto e médio prazo a existência de uma pluralidade de organismos regionais e sub-regionais continuará. O dilema é se nessa coexistência predominarão certos acordos para estabelecer âmbitos relativamente complementares ou se se dará uma competição mais aguda de acordos com a preponderância de alguns deles. O primeiro seria um cenário de aceitação de projetos de desenvolvimento diferentes (economias mais abertas ao comércio internacional e outras com um enfoque mais fechado), com o fortalecimento de valores comuns (direitos humanos e democracia) e espaços negociados para resolver os temas de segurança e a coordenação em assuntos em que o fator de proximidade geográfica é mais forte. O segundo implicaria a busca da primazia de um projeto alternativo em que a diferenciação tenderia a projetar-se em todas as áreas. O primeiro cenário daria espaço para levar em conta o interesse de todos os atores envolvidos, inclusive os países médios e pequenos, e o segundo estaria dominado pelas políticas externas dos mais fortes. Outro resultado possível seria a anulação da vontade coletiva e a prevalência das políticas externas de cada um dos países, com sério retrocesso nas formas associativas regionais. 


\section{Carlos Portales}

é diretor do Program on International Organizations, Law and Diplomacy no Washington College of Law (American University).

\section{Referências bibliográficas}

ALTMANN BORBON, J. 2011. "El Alba: entre propuesta de integración y mecanismo de cooperación”. Pensamiento Propio, n.33, pp.185-216.

BETETA, H. 2012. Central American development: two decades of progress and challenges for the future. Washington D.C.: Migration Policy Institute.

CEPAL. 2012. Panorama de la inserción internacional de América Latina y el Caribe 2011-2011. Santiago.

FLACSO. 2007. Dossier Comunidad Sudamericana de Naciones. San José de Costa Rica: Flacso.

FRITZ, T. 2007. "Alba contra Alca. La alternativa bolivariana para las Américas: una nueva vía para la integración regional en Latinoamérica”. Forschungs- und Dokumentazionszentrum ChileLateinamerika e.V. Berlin, Apr.

240 GIORDANO, P.; DEVLIN, R. 2011 "Regional integration". In: OCAMPO, J. A.; ROSS, J. (orgs.). The Oxford handbook of Latin American economics. Oxford: Oxford University Press.

GOLDMAN, R. K. 2009. "History and action: the Inter-American Human Rights System and the role of the Inter-American Commission on Human Rights". Human Rights Quarterly, v.31, n.4, pp.856-87.

GOMEZ MERA, L. 2005. "Explaining Mercosur's survival: strategic sources of Argentine-Brazilian convergence”. Journal of Latin American Studies, v.37, n.1, pp.109-40.

GUERRA BORGES, A. 2012. "La integración Latinoamericana, los primeros años”. In: BRICENO, J.; RIVAROLA, A.; CASAS, A. (orgs.). Integración latinoamericana y caribeña. Madrid: Fondo de Cultura Económica.

HERZ, M. 2008. "Does the Organization of American States Matter?" Crisis States Working Papers Series n. 2, London: CRSE-LSE Development Studies Institute. Apr.

MALAMUD, A. 2005. "Presidential diplomacy and the institutional underpinnings of Mercosur: an empirical examination". Latin American Research Review, v.40, n.1, pp.138-62. 
; GARDINI, J. L. 2012. "Has regionalism peaked? The Latin American quagmire and its lessons". The International Spectator: Italian Journal of International Affairs, v.47, n.1, pp.116-33.

MALLORQUIN, C. 2012. "La Cepal y Raúl Prebisch. La década de oro: 1950”. In: BRICENO, J.; RIVAROLA, A.; CASAS, A. (orgs.). Integración latinoamericana y caribeña. Madrid: Fondo de Cultura Económica.

PASQUALUCCI, J. 2003. The practice and procedure of the Inter-American Court of Human Rights. Cambridge: Cambridge University Press.

PENA, F. 2010a. "Integración regional y estabilidad sistémica en Suramérica”. In: CIENFUEGOS, M.; SANAHUJA, J.A. (orgs.). Una región en construcción. Unasur y la integración de América del Sur. Barcelona: Cidob.

2010b. Government Institutions and Regional Governance: towards a new map of cooperation in the Latin American space. Disponível em: $<$ www.felixpena.com.ar>. Acesso em: 17 out. 2012.

PORTALES, C. 2012. "Celac: a voice for Latin America and the Caribbean?" NOREF Report, Oslo: Norwegian Peace Building Resource Centre.

SANAHUJA, J. A. 2010. "La construcción de una región: Suramérica y el regionalismo posliberal”. In: CIENFUEGOS, M.; SANAHUJA, J. A. (orgs.). Una región en construcción. Unasur y la integración de América del Sur. Barcelona: Cidob.

2011. "Multilateralismo y regionalismo en clave suramericana: El caso de Unasur", Pensamiento Propio, n.33, pp.115-58.

SERBIN, A. 2010 Chávez, Venezuela y la reconfiguración política de América Latina y el Caribe. Buenos Aires: Siglo XXI.

SHAW, C. 2004. Cooperation, conflict, and consensus in the Organization of American States. New York: Palgrave Macmillan.

TISSOT, R. 2012. Latin America's energy future, Washington: IAD. (InterAmerican Dialogue Working Paper, Ago.). 


\section{PARA ONDE VAI O MULTILATERALISMO NAS AMÉRICAS? PROJETOS SUPERPOSTOS NUM PERÍODO DE MUDANÇAS GLOBAIS}

\section{CARLOS PORTALES}

Resumo: Para explicar a proliferação de organizações internacionais sub-regionais nas Américas após o fim da Guerra Fria, é necessário estudar as propostas dessas organizações, seus objetivos (integração ou cooperação política) e o lugar delas nas estratégias de política externa dos principais atores do Hemisfério, incluindo a forma como elas estão construindo suas relações com o novo sistema mundial. Uma análise das ações recíprocas entre antigas e novas organizações regionais e sub-regionais (levando em conta suas propostas, recursos e capacidades para coordenação política), do alcance de seus mandatos e do lugar que elas podem ter perante as instituições internacionais e poderes extra-hemisférios iluminará a nova estrutura do multilateralismo nas Américas.

Palavras-chave: Regionalismo; Sistema Interamericano; Organizações latino-americanas e caribenhas; Segurança; Direitos Humanos; Integração Econômica; Políticas Públicas.

\section{WHERE IS MULTILATERALISM GOING IN THE AMERICAS? OVERLAPPING ORGANIZATIONS IN A PERIOD OF GLOBAL CHANGE}

Abstract: To explain the proliferation of regional and sub-regional international organizations in the Americas after the end of the Cold War, it is necessary to study the purposes of such organizations, their objectives (integration or political cooperation) and the place they play in the foreign policy strategies of the main actors in the Hemisphere, including how they are building their relationships with the new global system. A review of the interplay among old and new regional and sub-regional organizations (taking into account its purposes, resources, and capabilities for policy coordination), 
the reach of their mandates, and the role they could have vis-à-vis global institutions and extra-hemispheric powers will illuminate the new structure of multilateralism in the Americas.

Keywords: Regionalism; Inter-American System; Latin American and Caribbean Regional Organizations; Security; Human Rights; Economic Integration; Public Policy.

Recebido: 08/05/2013Ａprovado: 15/08/2013 